\title{
Surgical outcomes in cardiogenic shock patients with preoperative extracorporeal membrane oxygenation (ECMO)
}

\author{
Mahmoud Yousef Ibrahim Abuharb®, Dong Ran*, Zheng Jubing ${ }^{*}$, Liu Taoshuai, Dong Haiming, Hou Xiaotong, \\ Song Yue, Zhao Yang and Li Yang
}

\begin{abstract}
Objectives: To summarise the surgical outcomes in patients with cardiogenic shock supported by preoperative extracorporeal membrane oxygenation (ECMO).

Methods: Between May 2012 and August 2017, eight patients with cardiogenic shock, who were supported by $E C M O$, underwent emergency surgery; four of them had isolated coronary artery bypass grafting, three had coronary artery bypass grafting with mitral replacement, and one had mitral valve replacement with left ventricular posterior wall repair.

Results: All eight patients were successfully weaned off from ECMO after their surgeries. Postoperative ECMO time ranged from 6.8 to $228.0 \mathrm{~h}$, with a median of $68.4 \mathrm{~h}$. Two patients died postoperatively while another six survived. The follow up time for the six patients ranged from three to 66 months, whereby one of them died in the third month due to septicaemia. The remaining five patients survived with good cardiac function based on the NYHA classification.

Conclusion: ECMO is a vital bridge in the preparation of critically-ill patients for cardiac surgery. It is associated with acceptable outcomes among most of the patients.
\end{abstract}

Keywords: Extracorporeal membrane oxygenation, Cardiogenic shock, Surgical treatment

\section{Introduction}

Extracorporeal Membrane Oxygenation (ECMO) was first applied clinically in $1973[1,2]$. Currently, ECMO is mainly used as circulatory assistance to rescue patients with acute circulatory and/or respiratory failure. Its two main purposes are to serve as a bridge-to-recovery (BTR) in patients who are suffering from heart failure and secondly, as a bridge-to-next decision (BTD) where it serves as a temporary intervention until further clinical decisions can be made. The examples of BTD include surgery, interventional treatment, long-term ventricular assist device (LVAD) implantation, heart transplantation [3], etc. To date, there are limited published studies on the surgical outcomes of cardiogenic shock patients supported by ECMO. We aimed to contribute to the literature by reporting on the ECMO cases in the Cardiac Surgery Department of Beijing Anzhen Hospital and to evaluate the surgical efficacy of ECMO on cardiac patients.

\section{Materials and methods}

This study was conducted from May 2012 to August 2017. All the patients with cardiogenic shock who received ECMO before emergency surgery were included (total of 8 patients). Patients with the following clinical

\footnotetext{
* Correspondence: mahmoudabuharb@dingtalk.com; 2258356549@qq.com Each of the authors confirms that this manuscript has not been previously published and is not currently under consideration by any other journal. Additionally, all of the authors have approved this paper's contents and have agreed to the policies of Journal of Cardiothoracic Surgery. Cardiovascular Surgery Department, Capital Medical University Affiliated Anzhen Hospital, Aiguo Road, Lianhe Avenue, Beijing 100029, China
}

(c) The Author(s). 2021 Open Access This article is licensed under a Creative Commons Attribution 4.0 International License, which permits use, sharing, adaptation, distribution and reproduction in any medium or format, as long as you give appropriate credit to the original author(s) and the source, provide a link to the Creative Commons licence, and indicate if changes were made. The images or other third party material in this article are included in the article's Creative Commons licence, unless indicated otherwise in a credit line to the material. If material is not included in the article's Creative Commons licence and your intended use is not permitted by statutory regulation or exceeds the permitted use, you will need to obtain permission directly from the copyright holder. To view a copy of this licence, visit http://creativecommons.org/licenses/by/4.0/. The Creative Commons Public Domain Dedication waiver (http://creativecommons.org/publicdomain/zero/1.0/) applies to the data made available in this article, unless otherwise stated in a credit line to the data. 
signs would be considered for ECMO support: systolic blood pressure $<90 \mathrm{mmHg}$, required two or more highdose vasopressors, intra-aortic balloon pump counterpulsation (IABP) needed to maintain blood pressure at $90 \mathrm{mmHg}$, peripheral vascular constriction, cold extremities, irritability, altered mental state, urine output $<30$ $\mathrm{ml} / \mathrm{h}$. High-dose vasopressor included dopamine $\geq 10 \mu \mathrm{g} /$ $\mathrm{kg} / \mathrm{min}$, adrenaline $\geq 0.05 \mu \mathrm{g} / \mathrm{kg} / \mathrm{min}$, dobutamine $\geq 1 \mu \mathrm{g} /$ $\mathrm{kg} / \mathrm{min}$, or milrinone $\geq 0.5 \mu \mathrm{g} / \mathrm{kg} / \mathrm{min}$.

A total of eight patients were included. Preoperatively, all eight patients were put on ECMO using Maquet (2050 package) or Medtronic pump head, as well as the Medos membrane lung combination. The MO loop was prefilled with lactated Ringer's solution or normal saline. The pulse-arterial ECMO (VA-ECMO) mode provided circulatory assistance through the femoral arteriovenous catheters. The intubation were all made of Medtronic Carmeda coating (19 Fr or $21 \mathrm{Fr}$ for vein, $15 \mathrm{Fr}$ or $17 \mathrm{Fr}$ for artery). Among these patients, two received percutaneous puncture catheterisation and six underwent incision catheterisation with the placement of distal irrigation. The ECMO operation was performed in the catheterisation lab for three of the patients, and in the EICU for another four patients. One patient underwent the procedure in the normal ward.

During ECMO, close monitoring was conducted every four hours to maintain the activated coagulation time (ACT) at $180-220 \mathrm{~s}$ and the activated partial thromboplastin time (APTT) at 50-60 s. Appropriate sedatives such as fentanyl, propofol, and dexmedetomidine were added to the intravenous pumps. The patients' conditions were closely monitored for any signs of recovery. All of the eight patients were supported with ECMO and mechanical ventilation. A protective lung ventilation strategy was adopted and the ventilator parameters were adjusted based on the blood gas results. When the patients showed good lung functions, sedation would be stopped and patients would be extubated. However, one of them awakened and had to proceed with ECMO without sedation. Bedside echocardiography was performed daily to assess the patients' cardiac function. If patients became haemodynamically stable, ECMO would be stopped for one hour. If the patients continued to be stable with good blood circulation and cardiac function, ECMO would be removed.

Operatively, all the eight patients underwent median sternotomy under general anaesthesia. Four patients underwent off-pump coronary artery bypass grafting (CABG) while on ECMO with an intraoperative ACT of $>380$ s. The other four patients underwent on-pump CABG coronary artery bypass grafting and they were heparinised to achieve ACT >480 s. Conventional ascending aorta cannulation, as well as superior and inferior vena cava cannulation, were established. The ECMO cannula was disconnected from the loop. Following that, the loop would be attached to a connector to turn it into a closed-loop self-circulation. The aortic cross-clamp was applied before starting the cardioplegia solution by cooling the heart surface with ice debris.

Surgically, three patients underwent coronary artery bypass surgery and mitral valve replacement. Another patient underwent routine mitral valve replacement with left ventricular posterior wall repair. In the operation, a sidewall clamp was first applied on the aorta while the proximal stapler was used to anastomose the proximal end of the target vessel before being moved down to perform distal anastomosis. The other four patients underwent simple CABG. All the bridging vessels used were the great saphenous veins. Of the total 15 grafts, five were for the anterior descending branch, one was for the diagonal branch, six for the circumflex branches, and three for the posterior descending branches. Mitral valve replacement was performed in four patients in which the posterior leaflet was retained and the intermittent suture was implanted. An artificial mechanical valve was used (Medtronic AP360 M24 or 26) for the patient with a ruptured posterior wall of the left ventricle as a result of visceral trauma. The valve was repaired with the intracardiac interrupted suture combined with the epicardial "sandwich" suture. All the patients were followed-up on November 30th 2017, via phone and by outpatient visits to determine their survivals and cardiac functions.

\section{Results}

There were six males and two females with an age range between 15 and 78 years-old $(55.5 \pm 15.5)$ and a weight range between 60 and $100 \mathrm{~kg}$. The preoperative ejection fraction was between 28 and $70 \%(52.0 \pm 14.0)$. The left ventricular end-diastolic diameter ranged between 43 and $65(54 \pm 7) \mathrm{mm}$ and the left ventricular end-systolic diameter was between 43 and $65(35 \pm 7) \mathrm{mm}$. Among them, six patients had an acute myocardial infarction, one patient had unstable angina, while another suffered from cardiac trauma. Three of them received cardiopulmonary resuscitation (Table 1).

The preoperative ECMO time ranged from 0.5 to 72.5 $(24.2 \pm 29.8)$ hours. The mean surgical time was $254.4 \pm 56.6$ min whereas the extracorporeal circulation time and the aortic block time were slightly lower at $139.3 \pm 34.0 \mathrm{~min}$ and $92.5 \pm 24.1 \mathrm{~min}$ respectively. Perioperative blood investigation showed red blood cells 6-46 U (median 11.5 U), plasma 400-2800 ml (median $900 \mathrm{ml}$ ), platelets 0-10 U (median 2.5 $\mathrm{U})$. Lastly, the postoperative-ventilator assistance time ranged from 37 to $546 \mathrm{~h}$, with a median of $162 \mathrm{~h}$.

All eight patients were successfully weaned off ECMO and ventilation. However, only six patients survived and were discharged from hospital, thus giving a survival rate 
Table 1 Preoperative characteristics of the patients

\begin{tabular}{|c|c|c|c|c|c|c|c|c|}
\hline Patient & 1 & 2 & 3 & 4 & 5 & 6 & 7 & 8 \\
\hline Gender & male & male & male & male & female & female & male & male \\
\hline Age & 59 & 63 & 78 & 15 & 62 & 56 & 47 & 64 \\
\hline Height (cm) & 175 & 175 & 170 & 170 & 175 & 160 & 175 & 168 \\
\hline Weight (kg) & 90 & 85 & 70 & 60 & 73 & 60 & 100 & 60 \\
\hline Diagnosis & AMl & AMI & unstable angina & cardiac trauma (posterior left ventricular rupture) & AMl & $\mathrm{AMl}$ & $\mathrm{AMI}$ & AMl \\
\hline MR & none & none & moderate & severe & severe & none & severe & severe \\
\hline CPR history & none & yes & yes & none & none & yes & none & none \\
\hline DM & none & none & yes & none & none & one & none & none \\
\hline HTN & yes & yes & yes & none & none & yes & yes & none \\
\hline Hyperlipidaemia & yes & yes & none & none & none & yes & none & none \\
\hline$E F(\%)$ & 43 & 28 & 54 & 60 & 70 & 65 & 52 & 43 \\
\hline LVDD & 50 & 49 & 50 & 60 & 55 & 43 & 65 & 59 \\
\hline
\end{tabular}

AMI Acute Myocardial Infarction, MR Mitral Regurgitation, EF Ejection Fraction, LVDD Left Ventricular End Diastolic Diameter

*Mitral Regurgitation was due to papillary muscle rupture

of $75 \%$. Postoperative ECMO assistance time ranged from 6.8 to $228 \mathrm{~h}$ with a median of $68.4 \mathrm{~h}$. There were two deaths $(25.0 \%)$ during the perioperative period, one of them died of septicaemia and multiple organ failure while another died of a stroke and multiple organ function. In addition, five patients (62.5\%) experienced renal failure after the operation and required dialysis. Two patients suffered from lung infections (25.0\%) and upper gastrointestinal bleeding (25.0\%) respectively. Type I respiratory failure occurred in one patient $(12.5 \%)$ and acute liver failure also occurred in one patient (12.5\%). All six cases were followed up after the operation. The follow up time ranged from 3 to 66 months with a mean of 12.5 months. However, one patient died of septicaemia three and a half months after the operation. The remaining five patients showed good cardiac functions with grade I NYHA classification (Table 2).

\section{Discussion}

A significant reduction in cardiac output can cause severe acute circulatory failure that is associated with a high mortality rate. The rate of hospitalised death due to

\begin{tabular}{ll}
\hline $\mathrm{n}$ & 8 \\
Male & 6 \\
Age Range & $47-78$ \\
Resuscitation & 4 \\
Diabetes & 1 \\
Hypertension & 6 \\
Moderate-Severe Mitral Regurgitation & 5 \\
EF & $52 \pm 13$ \\
LVDD & $53 \pm 6$ \\
\hline
\end{tabular}

cardiogenic shock can be as high as $80 \%$. Thus, it is important to reverse cardiogenic shock. In this study, emergency ECMO was used to assist the surgical treatment of cardiogenic shock. The subsequent in-hospital mortality rate was only $25.0 \%$. Although ECMO is generally used for cardiogenic shock after cardiac surgery [4], a recent study by Bastan et al. [5] recruited 517 patients who received ECMO as a result of postoperative cardiogenic shock. The ECMO removal rate was $63 \%$ and the survival rate was $24.8 \%$. The 6- and 12-month follow up survival rates were 17.6 and $16.5 \%$ respectively while the 5-year survival rate was $13.7 \%$. According to the study, the risk factors for in-hospital death included old age, preoperative renal insufficiency, diabetes, obesity, intraoperative lactic acidosis, and high scores of the European Heart Surgery Risk Assessment System (EuroScore).

In this study, the patients with cardiogenic shock received ECMO before surgery. The ECMO removal rate was $100 \%$ and the survival rate at discharge was $75 \%$. Thus, in comparison, preoperative implantation of ECMO is likely to confer a better prognosis than ECMO implantation after cardiac surgery. In a 2009 study by Bautista-Hernandez et al. [6], the surgical mortality was $38 \%$ among 26 patients who received a preoperative application of ECMO for congenital heart disease. Some of the complications of ECMO included death, inability to remove ECMO, and long-term dependence on ECMO. Another study in Taiwan reported a 50\% death rate among 16 cases of CABG patients who received ECMO reports [7]. Higher mortality was observed among those over 60 years old and those with severe hypoxic encephalopathy.

There are several limitations to this study. This was a retrospective study with a small number of cases. 
Table 2 Postoperative clinical characteristics of the patients

\begin{tabular}{|c|c|c|c|c|c|c|c|c|}
\hline Patient & 1 & 2 & 3 & 4 & 5 & 6 & 7 & 8 \\
\hline Pre-operative ECMO time (h) & 72.5 & 29.6 & 0.5 & 66.7 & 18 & 3.7 & 2 & 0.7 \\
\hline Post-operative ECMO time (h) & 16.5 & 136.4 & 66 & 6.8 & 135.5 & 70.8 & 228 & 40.3 \\
\hline ECMO total time $(\mathrm{h})$ & 89 & 166 & 66.5 & 73.5 & 117.5 & 74.5 & 230 & 41 \\
\hline Type of surgery & CABG & CABG & CABG & $\begin{array}{l}\text { Left ventricular posterior wall } \\
\text { repair + MVR }\end{array}$ & $\begin{array}{l}\text { CABG } \\
+\mathrm{MVR}\end{array}$ & CABG & $\begin{array}{l}\text { CABG } \\
+\mathrm{MVR}\end{array}$ & $\begin{array}{l}\text { CABG } \\
+ \\
\text { MVR }\end{array}$ \\
\hline Pre-Operative IABP & Yes & None & Yes & None & None & None & None & None \\
\hline Operation time (min) & 236 & 270 & 195 & 275 & 255 & 170 & 345 & 305 \\
\hline CPB time (min) & & & & 121 & 118 & & 190 & 128 \\
\hline Cross-clamp time (min) & & & & 87 & 78 & & 128 & 77 \\
\hline RBC (u) & 6 & 46 & 11 & 8 & 12 & 16 & 46 & 8 \\
\hline Plasma (ml) & 400 & 2800 & 400 & 1200 & 800 & 1000 & 2600 & 400 \\
\hline Platelet (u) & 3 & 10 & 1 & 0 & 4 & 2 & 3 & 0 \\
\hline Mechanical ventilation time (h) & 37 & 336 & 133 & 546 & 167 & 157 & 31 & 104 \\
\hline In-hospital death & None & Yes & None & None & None & None & Yes & None \\
\hline $\begin{array}{l}\text { Post-operative follow up time } \\
\text { (month) }\end{array}$ & 66 & NA & 17 & 17 & 8 & 5 & NA & 3 \\
\hline Follow up & Alive & $\begin{array}{l}\text { Died in } \\
\text { hospital }\end{array}$ & $\begin{array}{l}\text { Died } 3.5 \\
\text { months }\end{array}$ & Alive & Alive & Alive & $\begin{array}{l}\text { Died in } \\
\text { hospital }\end{array}$ & Alive \\
\hline $\begin{array}{l}\text { Follow up cardiac function } \\
\text { (NYHA class) }\end{array}$ & $\begin{array}{l}\text { Class } \\
1\end{array}$ & NA & NA & Class 1 & Class 1 & $\begin{array}{l}\text { Class } \\
1\end{array}$ & NA & $\begin{array}{l}\text { Class } \\
1\end{array}$ \\
\hline
\end{tabular}

CPB Cardiopulmonary Bypass, CABG Coronary artery bypass graft, MVR Mitral valve replacement, $h$ Hour, min Minute, IABP Intra-aortic balloon pump, ECMO Extracorporeal membrane oxygenation, NA Not applicable

\section{Conclusion}

In short, preoperative ECMO support in patients with cardiogenic shock provide critically-ill patients with opportunities for surgical treatment. It is also associated with better surgical outcomes.

\section{Abbreviations}

ECMO: Extracorporeal Membrane Oxygenation; NYHA: New York Heart Association; BTR: Bridge-to-Recovery; BTD: Bridge-to-Next Decision; ACT: Activated Coagulation Time; APTT: Activated Partial Thromboplastin Time; IABP: Intra-aortic Balloon Pump Counterpulsation; VA-ECMO: VenoArterial Extracorporeal Membrane Oxygenation; EICU: Electronic Intensive Care Unit; Cm: Centimetre; Kg: Kilogram; MR: Mitral Regurgitation;

CPR: Cardiopulmonary Resuscitation; DM: Diabetes Mellitus;

HTN: Hypertension; EF: Ejection fraction; LVDD: Left Ventricular End Diastolic Diameter; AMI: Acute Myocardial Infarction; N: Number; Min: Minute; H: Hour; Ml: Millilitre; U: Unit; CPB: Cardiopulmonary Bypass; MVR: Mitral Valve Replacement; EuroScore: European Heart Surgery Risk Assessment System

\section{Acknowledgements}

We would like to express our deepest gratitude to Professor Liu Tao Shuai for his patient guidance, enthusiastic encouragement, and useful critiques on this work. We would also like to extend our gratitude to the ECMO technicians for their great cooperation.

\section{Authors' contributions}

MYI wrote the manuscript. ZJB collected the relevant materials and medical records. DR performed the surgical procedure. All authors read and approved the final manuscript.

\section{Funding}

None.
Availability of data and materials

All data are available upon request from the Department of Cardiothoracic Surgery at Beijing Anzhen hospital.

\section{Declarations}

Ethics approval and consent to participate

Obtained.

\section{Consent for publication}

Written informed consent was obtained from all the patients. A copy of the written consent is available for review by the Editor of this journal.

\section{Competing interests}

None.

Received: 8 April 2021 Accepted: 19 May 2021

Published online: 03 August 2021

\section{References}

1. AbrAms D, Combes A, BroDie D. Extracorporeal membrane oxygenation in cardiopulmonary disease in adults [J]. J Am Coll CArdiol. 2014;63(25 PArt A): 2769-78.

2. ZApol WM, SniDer MT, Hill J, et al. Extracorporeal membrane oxygenation in severe acute respiratory failure: A randomized pro- spective study [J]. JAMA. 1979;242(20):2193-6. https://doi.org/10.1001/jama.1979.03300200023016.

3. Longcun HS, Jinping L, et al. Application of extracorporeal membrane oxygenation support therapy before heart transplantation. Chin J Extracorporeal Circ. 2005;3(4):236-8.

4. Xing $H$, Xiaolei $Y$, Hong $N$, et al. Extracorporeal membrane oxygenation adjuvant treatment of cardiogenic shock after cardiac surgery. Chin J Extracorporeal Circ. 2010;8(1):8-11.

5. RAstAn AJ, Dege A, MoHr M, et al. Early and late outcomes of 517 consecutive adult patients treated with extracorporeal mem- brane oxygenation for refractory 
postcardiotomy cardiogenic shock []]. J Thorac Cardiovasc Surg. 2010;139(2):302-11. https:/doi.org/10.1016/j.jtcvs.2009.10.043.

6. Bautista-Hernandez V, Thiagarajan RR, Fynn-Thopson F, et al. Preoperative extracorporeal membrane oxygenation as a bridge to cardiac surgery in children with congenital heart disease[]]. Ann Thorac Surg. 2009;88(4):130611. https://doi.org/10.1016/j.athoracsur.2009.06.074.

7. Wu MY, Tseng YH, YS CHA, et al. Using extracorporeal mem- brane oxygenation to rescue acute myocardial infarction with car- diopulmonary collapse: the impact of early coronary revasculariza- tion [J]. Resuscitation. 2013;84(7):940-5. https://doi.org/10.1016/j.resuscitation.2012.12.019.

\section{Publisher's Note}

Springer Nature remains neutral with regard to jurisdictional claims in published maps and institutional affiliations.

Ready to submit your research? Choose BMC and benefit from:

- fast, convenient online submission

- thorough peer review by experienced researchers in your field

- rapid publication on acceptance

- support for research data, including large and complex data types

- gold Open Access which fosters wider collaboration and increased citations

- maximum visibility for your research: over $100 \mathrm{M}$ website views per year

At $\mathrm{BMC}$, research is always in progress.

Learn more biomedcentral.com/submissions 